\title{
Epidemiology of rheumatic diseases in rural and urban populations in Indonesia: a World Health Organisation International League Against Rheumatism COPCORD study, stage I, phase 2
}

\author{
John Darmawan, Hans A Valkenburg, Kenneth D Muirden, Richard D Wigley
}

\begin{abstract}
To determine the incidence of musculoskeletal pain, disabilities, and help seeking behaviour, a questionnaire was administered to a rural population of 2184 men and 2499 women and an urban population of 481 men and 590 women aged over 15 years by house to house interviews with completion rates of

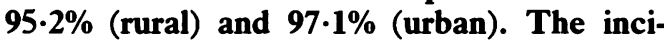
dences of pain in the joints, back, or neck were $23.6 \%$ (rural) and $31.3 \%$ (urban). The incidence of disability due to an inability to walk, lift, carry, and dress was $2 \cdot 8 \%$ (rural) and $0.9 \%$ (urban). The percentage of the population with pain who had to stop work owing to disability was $75 \%$ (rural) and $78 \%$ (urban). Official health care facilities were used by $62 \%$ (rural) and $71 \%$ (urban) of the population. Traditional health care was used by $87 \%$ (rural) and $89 \%$ (urban). The high percentage of subjects unable to work was due to a predominance of manual labour occupations (rural, $90 \%$, urban, $80 \%$ ). The age and sex specific incidence of rheumatic diseases in these populations were similar to other developing and developed countries. The primary rheumatology service was inadequate due to the low priority given by the health service to non-communicable diseases and inadequate rheumatology teaching of the primary health care doctors during undergraduate training. Musculoskeletal pain is a major public health problem in Indonesia and is still not fully appreciated.
\end{abstract}

The World Health Organisation (WHO) International League Against Rheumatism (ILAR) community oriented programme for the control of rheumatic disease (COPCORD) consists of three stages. ${ }^{1}$ In stage I epidemiological data on rheumatic disease are collected. In stage II the primary health care professionals are educated in the management of the most common rheumatic diseases. In stage III improved health care is attained. Stage I optimises the use of local skilled staff and the available resources in a three phase collection of data on rheumatic disease. $^{2}$

The objective of this study was to identify the scale of the problem of musculoskeletal pain and to collect data on existing help resources in a developing country. Based on the results of the incidence study, the stage II COPCORD or education of the primary health care professionals may be considered. This paper presents the results of COPCORD stage $I$, phase 2 in rural and urban areas of Indonesia.

\section{Patients and methods}

The total populations of 2499 women and 2184 men from two villages and the total populations of 590 women and 481 men from two city neighbourhoods, which were considered to be similar to the rural and urban population of Java, respectively, in demographic characteristics such as life expectancy, age structure, sex distribution, race, income, culture, religion, occupations, and social elass, ${ }^{34}$ were selected for a house to house interview survey designed to determine musculoskeletal pain, disability, and help seeking behaviour with the phase 2 questionnaire. The rural population consisted of $75 \%$ farmhands and farmers, $18 \%$ labourers, and $7 \%$ employed by motels, hotels, and village offices. They lived in well defined hamlets surrounded by rice fields and market gardens, mostly in thatched houses. The average life expectancy was 45 years for men and 50 for women, despite a heavier workload (Bandungan community health centre data, 1982) for the women.

The urban target areas were situated near the centre of a city with more than 900000 inhabitants with an average life span of 50 and 55 years for men and women, respectively. Its social strata was predominantly classes 5 (unskilled occupations) and 4 (partly skilled occupations) with some class 3 (skilled occupations) and very few classes 2 (intermediate occupations) and 1 (professional occupations). All the rural and urban target populations were Javanese (Malayo-Polynesians) except a negligible number (less than $0.5 \%$ ) of Chinese (Mongoloids) who were included in the urban subjects. ${ }^{34}$

The rural and urban populations were not socially stratified but were considered to represent the social strata of Javanese rural and urban populations.

The phase 1 questionnaire (omitted in this survey) records the occurrence of musculoskeletal pain in various body sites and disabilities as determined by primary health care workers ${ }^{2}$ Respondents from phase 1 with musculoskeletal diseases are interviewed by a nurse using the more detailed phase 2 questionnaire to identify definite rheumatic disease.

The phase 2 questionnaire (applied in this interview survey) contains identical questions to the phase 1 questionnaire with additional questions indicating possible rheumatoid arthritis, gout, and help seeking behaviour. The subjects with possible definite disease are then examined by a doctor familiar with rheumatic disease in phase 3 . This original screening

concept is designed to survey large sample \\ Department of
Epidemiology,
Medical Faculty
Erasmus Unive
Rotterdam, Rott
The Netherlands
J Darmawan
H A Valkenbur
Rheumatology
The Royal Mel
Hospital, Melbo
Australia
K D Muirden \\ Palmerston North \\ Palmerston N \\ New Zealand
}


populations in developing countries using minimal cost and manpower. ${ }^{6}$

Financial constraints allowed only one phase study. Therefore the phase 2 questionnaire was selected for application and phase 1 was omitted. The interview survey was carried out by a doctor and a nurse in the urban areas and two primary health care workers in two villages using the same questionnaire. Standardised training of the doctor and nurse in the urban study, and the primary health care workers in the rural study, trial runs of the questionnaire and checking by JD ensured that the survey was performed correctly.

Disability was defined only as inability to walk, lift, dress, or carry, ${ }^{5}$ excluding other disabilities of activities of daily living, and therefore underestimates total disability. Use of official health care facilities implied the attendance of a primary health care worker, nurse, and doctor at the community health centre for musculoskeletal pain. Traditional health care indicated treatment by a traditional healer, an acupuncturist, a masseur, or the use of herbs and self treatment with drugs.

\section{Results}

The response rates of the surveys were $95 \cdot 2 \%$ (rural) and $97 \cdot 1 \%$ (urban). Peripheral joint pain occurred at a similar rate in men and women, increasing with increasing age, and was significantly more common in the urban than the rural areas. Neck, upper back, lower back pain, back pain at any site, pain at any site, restricted range of neck movement, and limited back movement as shown by the respondents and recorded by the interviewers, were also more common in the urban than the rural respondents, without significant sex differences (table 1). Lower back pain and back pain at any site were higher in rural men and urban women.

Disability was more common among men than women in the two studies. Of the rural respondents with pain and any type of disability, $78 \%$ of men and $73 \%$ of women had to stop work, particularly those who could not lift and, to a lesser extent, those unable to walk or carry. These figures for the urban respondents were $81 \%$ for men and $76 \%$ for women. Official health centres were used by $70.5 \%$ of the urban compared with $62.0 \%$ of the rural population with musculoskeletal pain.
Of those with pain, more than $60 \%$ had visited the rural or urban community health centre, doctor, nurse, or primary health care worker and this help seeking was higher for urban women. In addition to the official health centre most had also sought help from two or more traditional health care sources for the relief of musculoskeletal pain. Pain relief was most commonly sought by buying whichever antirheumatic drugs were available without prescription. This applied particularly to urban men and women who also used herbal remedies more often. Massage was used less often in the city, particularly by women. Acupuncture was used by less than $10 \%$ of respondents with no differences between rural and urban areas and the sexes. In all, more than $86 \%$ of the rural and $88 \%$ of the urban positive respondents had sought traditional medical relief for their pain. The nurse and primary health care worker were less often used in the city. The traditional healer was rarely used in the city.

\section{Discussion}

With the translation of the standard English COPCORD questionnaire into the official Indonesian language, cross cultural differences became apparent between the two languages in vocabulary, idioms, and grammar. While interviewing the subjects, cross cultural differences in activities of daily living between a developed and a developing country hampered the application of several questions.

By rephrasing the English questions without cross cultural equivalence in language and discarding answers to activities of daily living without cross cultural analogues, some loss of validity and ascertainment were unavoidable. This was evident with several questions on morning stiffness, crepitus, low back pain, past pain, and perceived need for help. Morning stiffness had almost zero sensitivity due to a language barrier and the answers to the morning stiffness question were not analysed. Sacral pain was taboo in the rural areas and was not asked about, thereby underestimating total low back pain compared with the urban total low back pain. As even dramatic past events such as melaena or haematemesis were often forgotten, ${ }^{6}$ answers to queries on past pain were not analysed. Questions on perceived need for help needed to be redefined for populations living in

Table 1 Incidence of musculoskeletal pain in 4683 rural and 1071 urban subjects aged 15 years and over. Results given as percentages and significant differences between areas

\begin{tabular}{|c|c|c|c|c|c|c|}
\hline & \multicolumn{2}{|l|}{ Rural } & \multicolumn{2}{|l|}{ Urban } & \multicolumn{2}{|l|}{ Rural/urban } \\
\hline & $\underset{(n=2184)}{M e n}$ & $\begin{array}{l}\text { Women } \\
(n=2499)\end{array}$ & $\begin{array}{l}M e n \\
(n=481)\end{array}$ & $\begin{array}{l}\text { Women } \\
(n=590)\end{array}$ & $\begin{array}{l}\text { (Men and wo } \\
(n=4693)\end{array}$ & $\begin{array}{l}\text { omen }) \\
(n=1071)\end{array}$ \\
\hline \multicolumn{7}{|l|}{ Location of pain: } \\
\hline Peripheral joints & $16 \cdot 8$ & $18 \cdot 7$ & $25 \cdot 1$ & $29 \cdot 4$ & $* *$ & $* *$ \\
\hline Neck & $4 \cdot 4$ & $5 \cdot 2$ & $10 \cdot 8$ & $12 \cdot 5$ & *** & $* *$ \\
\hline Restricted neck movement & $0 \cdot 4$ & $0 \cdot 7$ & $2 \cdot 3$ & $1 \cdot 4$ & & \\
\hline Upper back & $5 \cdot 7$ & $5 \cdot 0$ & $\overline{7} \cdot \overline{7}$ & $10 \cdot 1$ & & \\
\hline Lower back & $17 \cdot 4$ & $13 \cdot 1$ & $19 \cdot 4$ & $25 \cdot 6$ & & ** \\
\hline Back pain, any site & $18 \cdot 2$ & $13 \cdot 6$ & $24 \cdot 9$ & $26 \cdot 8$ & ** & ** \\
\hline Limited back movement & $0 \cdot 3$ & $0 \cdot 3$ & $3 \cdot 0$ & $2 \cdot 4$ & $* *$ & $* *$ \\
\hline Back pain ref. to legs and feet & $9 \cdot 4$ & $7 \cdot 9$ & $7 \cdot 9$ & $9 \cdot 9$ & & \\
\hline Pain, any site & $24 \cdot 5$ & $22 \cdot 9$ & $29 \cdot 4$ & $32 \cdot 9$ & & ** \\
\hline Disability, one or more joints & 3.4 & $2 \cdot 2$ & $1 \cdot 8$ & 0.3 & & $* *$ \\
\hline
\end{tabular}


deprived socioeconomic circumstances as they inevitably elicited an affirmative answer, reflecting financial rather than health needs.

To undertake future comparative epidemiological surveys, the study design and questionnaire from developed countries requires field testing in the cross cultural equivalence of questions in language and activities of daily living and occupations. Translation from one culture to another must use terms referring experiences exactly similar or at least familiar. ${ }^{7}$ Future studies with improved cross cultural field tested questionnaires will eliminate most of the problems encountered and generate better data for comparison.

The very high response rates were due to the perseverance of the primary health care workers, nurse, and doctor in collecting data on missing respondents. Response rates of up to $99 \cdot 0 \%$ have also been achieved in earlier interview surveys about rheumatic diseases. ${ }^{8}$

The incidence of musculoskeletal pain in all sites was significantly higher in the urban than the rural populations (table 1). This may be partly due to the fact that the doctor and nurse could elicit more problems than the primary health care workers from the more literate urban populations. On the other hand, the rural population may have been more stoical about trivial aches and pains due to repetitive physical strenuous labour. Nevertheless, interobserver variations were unavoidable given the different professional backgrounds of the interviewers and this may have influenced the determined incidence of musculoskeletal pain.

There were no significant differences between the pain and rates at individual pain sites in the Indonesian phase 2 and the Philippines phase 2 COPCORD study, ${ }^{2}$ except lumbar pain (table 2). The Indonesians had more than twice the rate of lower back pain (17\%, rural) than Filipinos. There was no explanation for this significant difference.

Table 2 Age standardised comparison of rates of pain as percentages in major pain groupings in the Indonesian and the Philippines COPCORD phase 2 interview survey

\begin{tabular}{lccc}
\hline Pain group & Indonesia & \multicolumn{2}{l}{$\begin{array}{l}\text { The Philippines } \\
\text { (ref. 2) }\end{array}$} \\
\cline { 2 - 3 } & Rural & Urban & Rural \\
\hline Neck & $4 \cdot 8$ & $11 \cdot 8$ & $5 \cdot 1$ \\
Upper back & $5 \cdot 3$ & $9 \cdot 3$ & $5 \cdot 5$ \\
Lower back & $15 \cdot 1$ & 23.3 & $7 \cdot 5$ \\
Peripheral joint & $17 \cdot 8$ & 27.8 & $18 \cdot 2$ \\
Total pain rate & 23.6 & 31.6 & 28.4 \\
\hline
\end{tabular}

The disability rate as defined was low, but it was considered that no cases of severe disability were missed because the likelihood of concealment was small as a result of cramped living conditions. The lower disability rate in the urban population may be partly due to the easy access to secondary and tertiary health care facilities.

More than $90 \%$ of the rural and $80 \%$ of the populations were engaged in heavy manual labour such as lifting and carrying heavy loads, or walking some distance to break the soil of rice fields using a short handled hoe. This may explain the high percentage of work stoppage. Though there were differences recorded in the different disabilities between the Philippines and Indonesia, the total disability rate was similar $(2 \cdot 7 v 2 \cdot 8 \%)^{2}$

The more frequent use of traditional compared with official health care facilities (table 3) may indicate the easy accessibility and low cost of traditional health care, though both were inadequate for coping with rheumatic disease. Self treatment with drugs was most common with a combination of $5 \mathrm{mg}$ prednisone, $200 \mathrm{mg}$ phenylbutazone, and $300 \mathrm{mg}$ paracetamol buffered with antacids. The combination of drugs taken was one tablet three times a day, and although taken intermittently due to financial limitations, this constituted a high dose corticosteroid treatment with possible long term side effects. The annual per capita consumption of the drug combination for the inhabitants of the province was 12 tablets. Several popular herb capsules, local or imported, were found to contain a similar drug combination when analysed. The use of this combined drug was widespread and available over the counter at drug stores to the 108 million people on the island of Java seeking relief for musculoskeletal pain.

Twice as many urban respondents visited a doctor $(50 \%)$ compared with the rural respondents $(25 \%)$. Projecting statistics on rheumatic disorders from primary, secondary, and tertiary health care centres serving defined areas and populations as incidence rates will obviously be a gross underestimate. Even in a developed country such as the Netherlands, $22 \%$ of women and $29 \%$ of the men with rheumatoid arthritis had never been a patient. ${ }^{8}$ In England $19 \%$ of men and $38 \%$ of women with rheumatoid arthritis were never seen by doctors. ${ }^{9}$

Comparing the age and sex specific incidence of musculoskeletal pain with results from

Table 3 Type of treatment sought by 4683 rural and 1071 urban subjects aged 15 years and over with musculoskeletal pain. Results given as percentages and their significance differences between the areas

\begin{tabular}{|c|c|c|c|c|c|c|}
\hline & \multicolumn{2}{|l|}{ Rural } & \multicolumn{2}{|l|}{ Urban } & \multicolumn{2}{|l|}{ Rural/urban } \\
\hline & $\begin{array}{l}\text { Men } \\
(n=2184)\end{array}$ & $\begin{array}{l}\text { Women } \\
(n=2499)\end{array}$ & $\begin{array}{l}\text { Men } \\
(n=481)\end{array}$ & $\begin{array}{l}\text { Women } \\
(n=590)\end{array}$ & $\begin{array}{l}\text { (Men and wo } \\
(n=4693)\end{array}$ & $\begin{array}{l}\text { omen }) \\
(n=1071)\end{array}$ \\
\hline \multicolumn{7}{|l|}{ Treatment sought: } \\
\hline Official health care & $60 \cdot 4$ & $63 \cdot 5$ & $64 \cdot 1$ & $74 \cdot 0$ & & $* *$ \\
\hline Non-prescribed drugs & $54 \cdot 8$ & $63 \cdot 5$ & $72 \cdot 6$ & $76 \cdot 3$ & $* *$ & $* *$ \\
\hline Traditional health care & $85 \cdot 8$ & $87 \cdot 6$ & $89 \cdot 7$ & $88 \cdot 1$ & & \\
\hline Herbs & $46 \cdot 9$ & $49 \cdot 5$ & $56 \cdot 4$ & $65 \cdot 3$ & $* *$ & ** \\
\hline Massage & $53 \cdot 1$ & $52 \cdot 8$ & $46 \cdot 2$ & $35 \cdot 5$ & & $* *$ \\
\hline Healer & $13 \cdot 8$ & $9 \cdot 1$ & & & & \\
\hline Acupuncture & 6.5 & $7 \cdot 0$ & $9 \cdot 4$ & $9 \cdot 1$ & & \\
\hline
\end{tabular}


Table 4 Age and sex-specific pain rates at any site in different populations in men and women (as percentages)

\begin{tabular}{|c|c|c|c|c|c|c|c|c|c|c|}
\hline \multirow[t]{3}{*}{ Age (years) } & \multicolumn{4}{|c|}{ Indonesia } & \multirow{2}{*}{\multicolumn{2}{|c|}{$\frac{\text { Philippines }^{2}}{\text { Rural }}$}} & \multicolumn{2}{|c|}{ England } & \multicolumn{2}{|c|}{ EPOZ Holland ${ }^{7}$} \\
\hline & \multicolumn{2}{|c|}{ Rural } & \multicolumn{2}{|c|}{ Urban } & & & \multirow[b]{2}{*}{ Men } & \multirow[b]{2}{*}{ Women } & \multirow[b]{2}{*}{ Men } & \multirow[b]{2}{*}{ Women } \\
\hline & Men & Women & Men & Women & Men & Women & & & & \\
\hline $\begin{array}{l}15-24 \\
25-34 \\
35-44 \\
45-54 \\
55-64 \\
65+\end{array}$ & $\begin{array}{l}8 \\
20 \\
28 \\
40 \\
45 \\
57\end{array}$ & $\begin{array}{r}7 \\
18 \\
27 \\
43 \\
47 \\
55\end{array}$ & $\begin{array}{r}9 \\
15 \\
28 \\
43 \\
62 \\
74\end{array}$ & $\begin{array}{l}10 \\
23 \\
36 \\
48 \\
54 \\
60\end{array}$ & $\begin{array}{r}8 \\
25 \\
41 \\
45 \\
56 \\
69\end{array}$ & $\begin{array}{l}15 \\
30 \\
25 \\
47 \\
49 \\
56\end{array}$ & $\begin{array}{r}9 \\
20 \\
19 \\
33 \\
47 \\
39\end{array}$ & $\begin{array}{r}9 \\
16 \\
32 \\
41 \\
63 \\
52\end{array}$ & $\begin{array}{l}\overline{23} \\
26 \\
38 \\
39 \\
30\end{array}$ & $\begin{array}{l}\overline{24} \\
32 \\
50 \\
54 \\
51\end{array}$ \\
\hline $\begin{array}{l}15-65+ \\
25-65+\end{array}$ & $\begin{array}{l}25 \\
31\end{array}$ & $\begin{array}{l}23 \\
31\end{array}$ & $\begin{array}{l}29 \\
36\end{array}$ & $\begin{array}{l}33 \\
40\end{array}$ & $\begin{array}{l}27 \\
34\end{array}$ & $\begin{array}{l}30 \\
38\end{array}$ & $\begin{array}{l}28 \\
32\end{array}$ & $\begin{array}{l}38 \\
43\end{array}$ & $\overline{31}$ & $\overline{41}$ \\
\hline $\begin{array}{l}15-65+(\text { men }+ \\
\text { women) } \\
25-65+(\text { men }+ \\
\text { women })\end{array}$ & \multicolumn{2}{|c|}{24} & \multicolumn{2}{|c|}{32} & \multicolumn{2}{|c|}{25} & \multicolumn{2}{|c|}{29} & \multicolumn{2}{|c|}{33} \\
\hline
\end{tabular}

England ${ }^{10}$ and the EPOZ study in the Netherlands, ${ }^{11}$ the rates for the $25-65+$ year old age groups for men and women were remarkably similar (Table 4). It should be realised however, that cross cultural differences in the design, type, and quality of observers used, and variations of pain and complaint threshold due to linguistic and cultural differences could have influenced the results. On the other hand, it is conceivable that musculoskeletal pain is ubiquitous and that in this respect people around the world react in almost the same way to perceived pain.

The district hospital did not have a physiotherapy department, traditional health care was ineffective, and self help led to self treatment with corticosteroids. Antirheumatic drugs available in the community health centre consisted of paracetamol, phenylbutazone, methampyrone, aspirin, and prednisone. Without a simple laboratory, the community health centre, serving a total population of 38500 people, cannot perform regular control studies of full blood analyses and thrombocytes count on patients receiving long term treatment with phenylbutazone and dipyrone. With the provision of one session of physical examination and a supply of medicines for three days, the primary health care centre was not equipped for treatment of the most common chronic arthritis such as osteoarthritis. Referral to a rheumatologist was impossible as the ratio of rheumatologist to the total population of the country was 1 to 18 million. Management of the (rare) patients with severe rheumatic disease (such as rheumatoid arthritis or systemic lupus. erythematosus) was unheard of.

Despite the lack of skilled manpower and financial constraints the Indonesian, COPCORD had identified the magnitude of the problem of musculoskeletal pain and the inadequacy of existing resources. Skill, treatment facilities, and equipment to cope with $80 \%$ of the rheumatic problems (neck and back pain, soft tissue rheumatism, arthritis, and disabilities) were simply inadequate. Primary health care workers cannot adequately cope with the most common rheumatic disorders because of inadequate rheumatology teaching during undergraduate training.

Musculoskeletal pain is a major public health problem which is still not appreciated and is without adequate health services in developing countries. COPCORD Stage II may be of immediate relevance. ${ }^{1}$

Supported in part by an educational grant from Ciba-Geigy and Pfizer Indonesia, the World Health Organisation, and the Asia Pacific League Against Rheumatism.

1 Grabaukas V. A World Health Organization perspective. f Rheumatol Suppl 1983; 10: 5-6.

2 Manahan L, Caragay R, Muirden K D, Allander D, Vanahan L, Caragay R, Muirden K D, Allander D,
Valkenburg H A, Wigley R D. Rheumatic pain in a Valkenburg H A, Wigley R D. Rheumatic pain in

Philippine village. Rheumatology Int 1985; 5: 149-53.
3 Indonesian statistics in numbers in 1981, fakarta. The National Statistics of Indonesia: Demographic Data.

4 Central fava in numbers in 1981: demographic data, Central Java Office of Statistics.

5 Wigley R D, Manahan L, Caragay R, et al. Observation on rheumatic disease in Polynesia and the Philippines. F Rheumatol Suppl 1983; 10: 37-9.

6 Corvin R G, Krober M, Roth H P. Patient's accuracy in reporting their past medical history, a study of 90 patients with peptic ulcer. $\mathcal{f}$ Chronic Dis 1971; 23: 875.

7 Ferraz M B, Oliveira L M, Araujo P M P, et al. Crosscultural reliability of the physical ability dimensions of the health reliability of the physical ability dimensions of the health
assessment questionnaire. I Rheumatol 1990; 17: 813-7.

8. Valkenburg H A. Epidemiologic consideration of the geriatric population. Gerontology 1988; 34 (suppl 1): 2-10.

9 Kellgren J H, Lawrence J S, Aitken-Swan J. Rheumatic complaints in an urban population. Ann Rheum Dis 1953; 12: $5-15$.

10 Lawrence J S. Rheumatism in populations. London: Heineman Medical Books, 1977: 9, 40-67, 91, 98-111, 131, 206, 359, 410.

11 Valkenburg H A. EPOZ Report 1979; 4: 4.19. 